\title{
The Extreme Decline of Investor Sentiment and Market Efficiency: Evidence from the Electric Appliances Industry in Japan
}

\author{
Chikashi Tsuji (Corresponding author) \\ Graduate School of Systems and Information Engineering, \\ University of Tsukuba \\ 1-1-1 Tennodai, Tsukuba, Ibaraki 305-8573, Japan \\ Tel: +81-29-853-2111 E-mail: mail_sec_low@minos.ocn.ne.jp
}

Received: March 12, 2012

Accepted: March 31, 2012 Published: April 1, 2012

doi:10.5296/jmr.v4i2.1505

URL: http://dx.doi.org/10.5296/jmr.v4i2.1505

\begin{abstract}
This paper aims to clarify whether weak form market efficient hypothesis holds in markets with deteriorated investor sentiment by focusing on the return dynamics of the Japanese electric appliances industry stocks. The contributions derived by our empirical analysis are as follows. First, this paper revealed that when investor sentiment is very stable, two successive days' returns have no relation. Hence in markets with very stable sentiment, weak form market efficient hypothesis holds. Second, we clarified that when investor sentiment is deteriorated, two successive days' returns are statistically significantly connected. Therefore, in markets with extremely declined investor sentiment, weak form market efficient hypothesis does not hold.
\end{abstract}

Keywords: Implied volatility, Investor sentiment, Market Efficiency 


\section{Introduction}

Investor sentiment in financial markets is more and more important as increasing studies on this topic show. Representative researches regarding this market sentiment were conducted by such studies as Lee et al. (1991), Barberis et al. (1998), Neal and Wheatley (1998), Daniel et al, (1998), Baker and Wurgler (2006), and Baker and Wurgler (2007). Moreover, many new studies follow the above papers are also seen in Tsuji (2006), Kurov (2010), Berger and Turtle (2012), Baker et al. (2012), Alimov and Mikkelson (2012), and Stambaugh et al. (2012). However, as far as we know, there seems to be little study which tests the market efficiency when market sentiment is extremely declined. Therefore, this paper aims to clarify whether weak form market efficient hypothesis of Fama (1970) holds in markets with deteriorated investor sentiment. This is our main objective of this paper. We focus on the Japanese electric appliances industry stocks because this is one of the most representative industries in Japan.

Our contributions in this paper are as follows. First, this paper reveals that when investor sentiment is very stable, two successive days' returns have no relation. Thus in markets with very stable sentiment, weak form market efficient hypothesis holds. Further, we also clarify that when investor sentiment is deteriorated, two successive days' returns have statistically significant relations. Hence in markets with extremely declined investor sentiment, weak form market efficient hypothesis does not hold. This finding is the most important contribution in this paper.

The rest of the paper is organized as follows. First, Section 2 explains the research design and data for our analysis, Section 3 documents the empirical results and interpretation, and Section 4 concludes the paper.

\section{Data and Research Design}

First, we define the markets with extremely declined sentiment and the markets with very stable sentiment. We use the implied volatility (IV) derived from the Nikkei 225 options as an investor sentiment measure of stock markets. The data are from Osaka University, and the full sample period of our daily IV data is from January 5, 1998 to April 28, 2011. By using these IV values, for our empirical tests, we first set extremely low IV dates as those when IV is less than the value of 13.5. On the other hand, we regard extremely high IV dates as those when IV exceeds the value of 80.0. As displayed from Panels A to M of Figure 1, only 13 days are recognized as extremely low IV dates. Namely, these thirteen days are the dates when market sentiment is very stable in our research design. More specifically, those days are February 6, 2004, November 26, 2004, March 22, 2005, April 1 and 4, 2005, June 16, 23, 24, and 28, 2005, July 1, 4, 5, and 6, 2005. On the other hand, as shown from Panels A to K of Figure 2, only 11 days are recognized as extremely high IV dates. That is, these eleven days are the dates when market sentiment is deteriorated in our setting. More specifically, those days are October 16, 27, 28, 29, 30, and 31, 2008 and November 4, 7, 13, 20, and 21, 2008.

Based on the above setting, by also using return data of 116 Japanese electric appliances industry firms (from Nikkei Inc.) we perform the following cross-sectional regression. 


$$
R E T_{i}^{\text {day } t}=\psi_{0}+\psi_{1} R E T_{i}^{\text {day } t-1}+\tau_{i}
$$

Where the dependent variable is the return of the day when investor sentiment is very stable or deteriorated, and the explanatory variable is the return of the prior day when investor sentiment is very stable or deteriorated. This regression means the test for weak form market efficient hypothesis, because if weak form market efficient hypothesis holds, two successive returns have no relation. (For example, see Brealey et al. (2008) and Fama (1970).) To investigate the situation in markets with stable or deteriorated investor sentiment, we focus on the dates when IV is less than 13.5 and the dates when IV exceeds 80.0. Further, before implementing our regression (1), we check the correlation coefficients of two successive days' returns in markets with stable or deteriorated investor sentiment with viewing their return plots.

Regarding return data, they are 116 Japanese electric appliances industry companies' returns, and these companies are listed in the Tokyo Stock Exchange (TSE) First Section. Currently, the number of the electric appliances industry companies is largest in the Tokyo Stock Price Index (TOPIX). Thus we consider that this industry is highly important for the Japanese stock markets. Hence we use these companies' data in this paper. In addition, we use the method of White (1980) in our cross-sectional regressions, thus statistical significance of the coefficients of our regressions is robust to the heteroskedasticity of regression error terms.

\section{Empirical Results}

This section describes our empirical results. First, we view the return plots with checking the correlations of two successive business days' returns in markets with stable investor sentiment. As shown in Panels A to M in Figure 1, when market sentiment is very stable, correlation coefficients generally take the low values between -0.1241 to 0.2752 and the return plots generally do not focus on any quadrants. On the other hand, as indicated in Panels A to K in Figure 2, when market sentiment is deteriorated, correlation coefficients generally take the high values between -0.4597 to 0.4594 and the return plots often focus on some quadrants.

Second, more formally, Panel A of Table 1 indicates the regression results when market sentiment is very stable. In this panel, there exists no statistically significant coefficient in regression (1). Hence we understand that in the stable sentiment stock markets, the weak form market efficient hypothesis strictly holds. On the other hand, Panel B of Table 1 demonstrates the regression results when market sentiment is extremely declined. In this panel, out of eleven cross-sectional regression results, seven cases indicate the statistically significant connections between two successive business days' returns. Therefore, from this evidence, we can judge that in markets with deteriorated investor sentiment, weak form market efficient hypothesis does not hold. 
Panel A. February 6, 2004

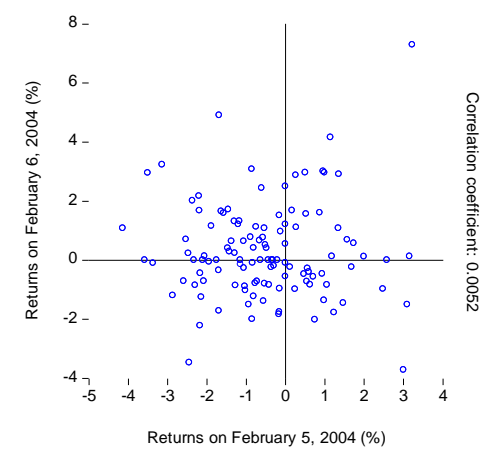

Panel C. March 22, 2005

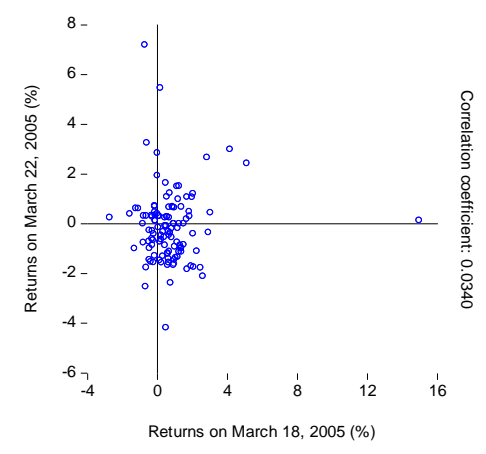

Panel E. April 4, 2005

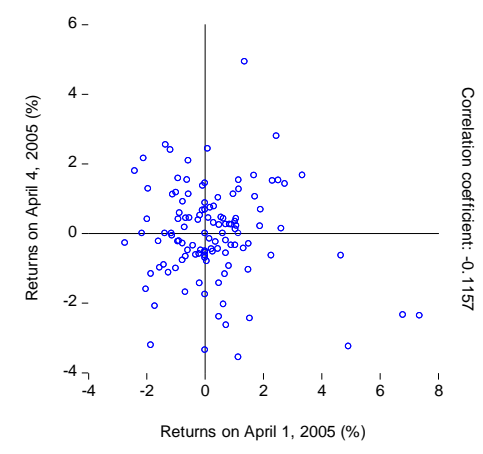

Panel G. June 23, 2005

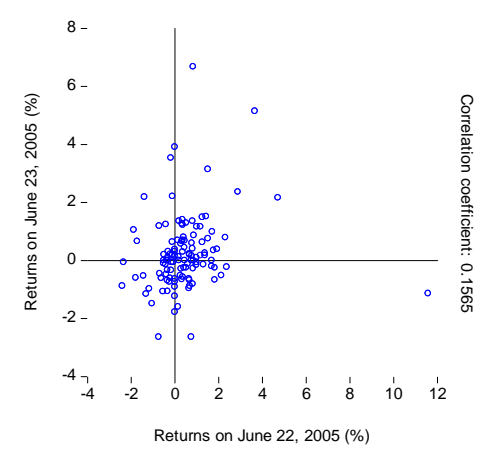

Panel B. November 26, 2004

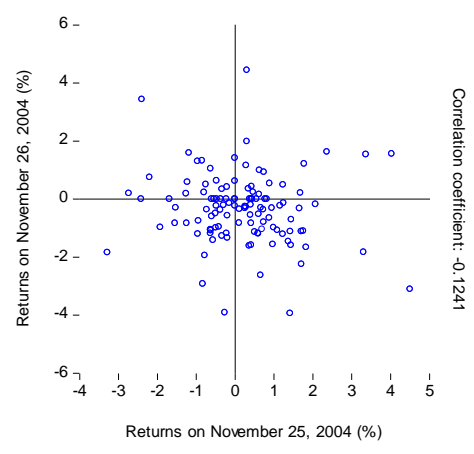

Panel D. April 1, 2005

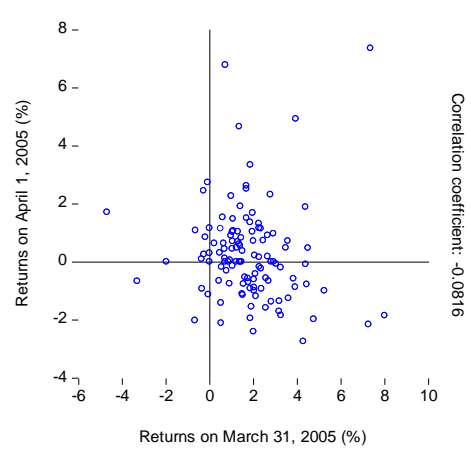

Panel F. June 16, 2005

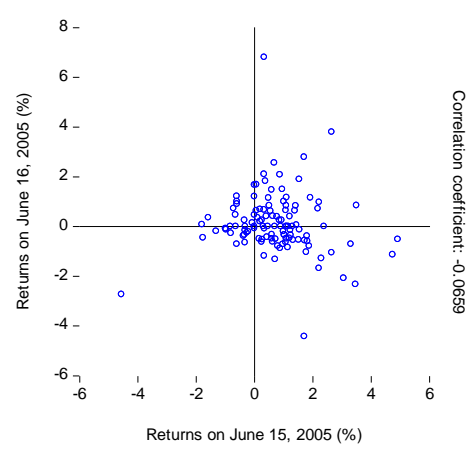

Panel H. June 24, 2005

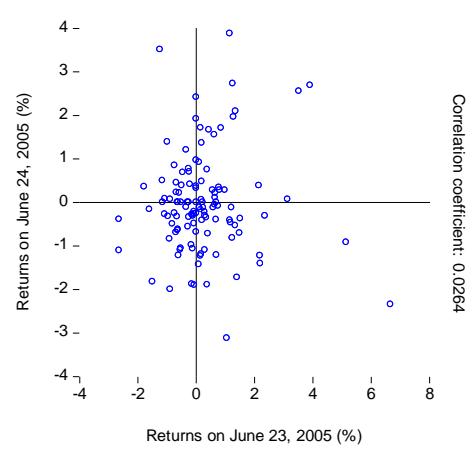




\section{MInstitute ${ }_{\text {Mntw }}^{\text {Macrothink }}$}

Panel I. June 28, 2005

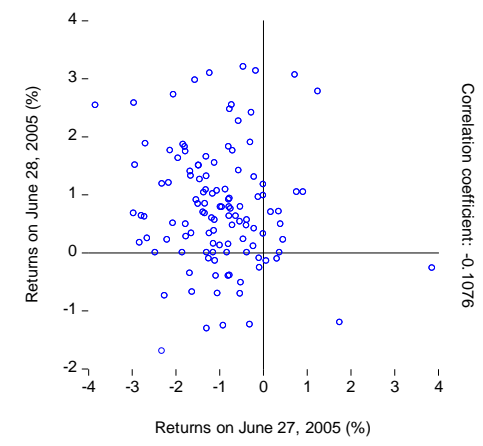

Panel K. July 4, 2005

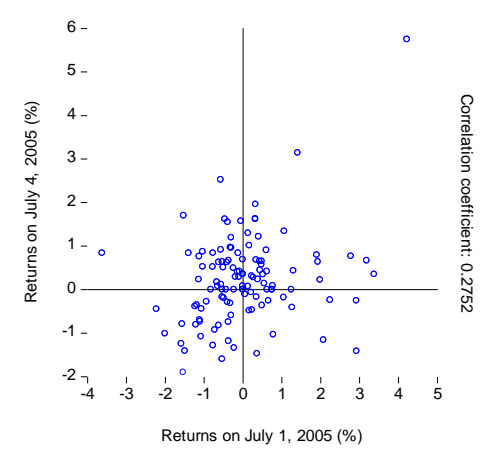

Journal of Management Research ISSN 1941-899X 2012, Vol. 4, No. 2
Panel J. July 1, 2005

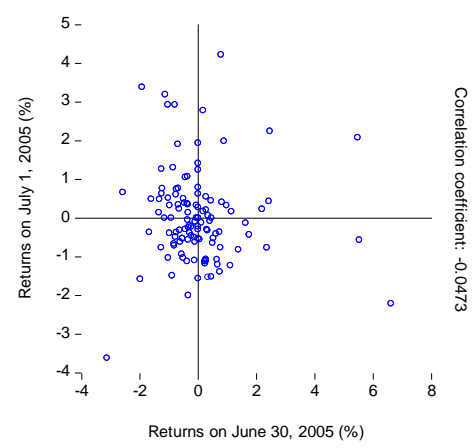

Panel L. July 5, 2005

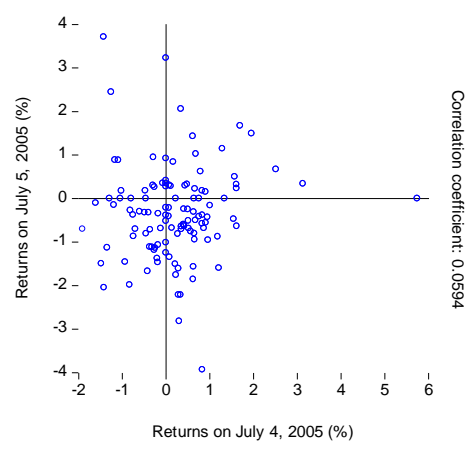

Panel M. July 6, 2005

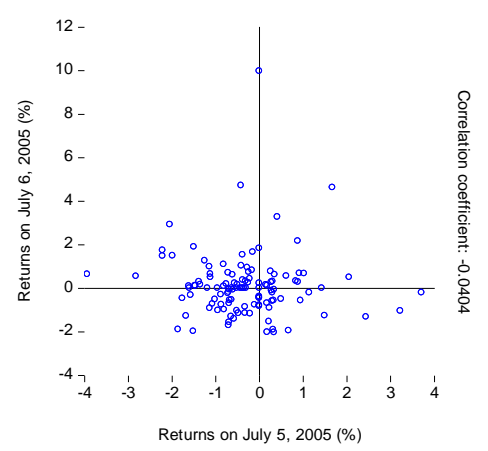

Figure 1. Japanese Electric Appliances Industry Returns of Two Successive Business Days When Implied Volatility is Less than 13.5.

Panel A. October 16, 2008

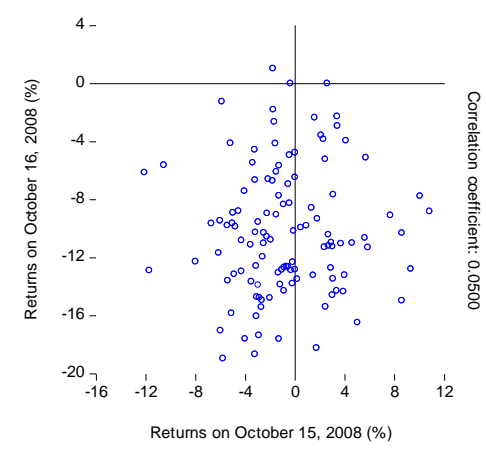

Panel B. October 27, 2008

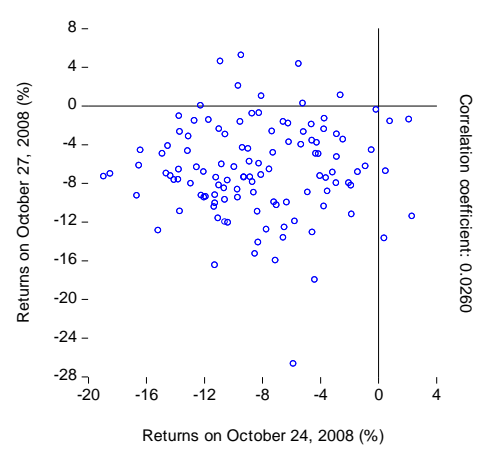




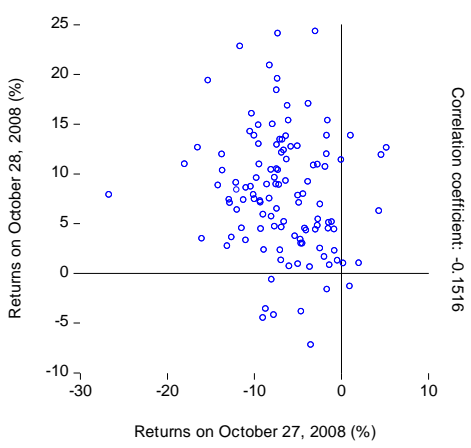

Panel E. October 30, 2008

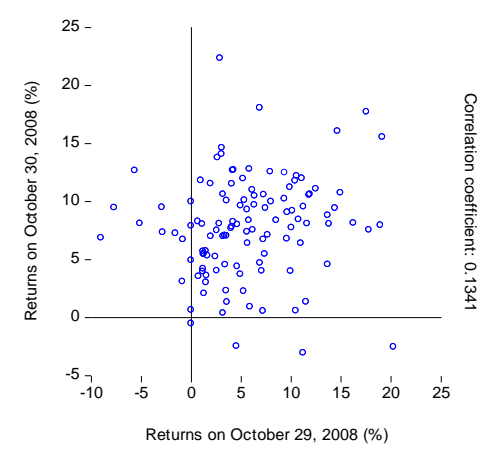

Panel G. November 4, 2008

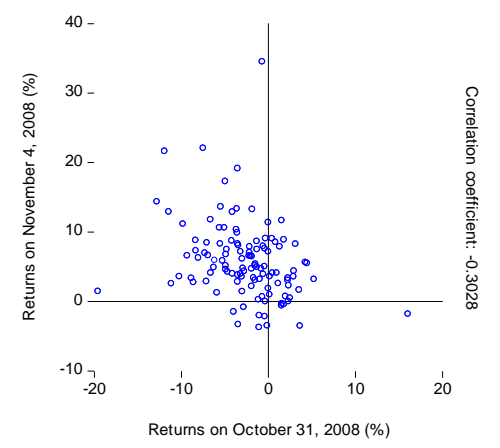

Panel I. November 13, 2008

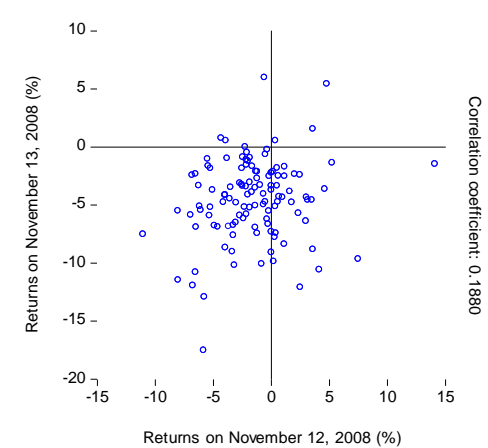

Panel D. October 29, 2008

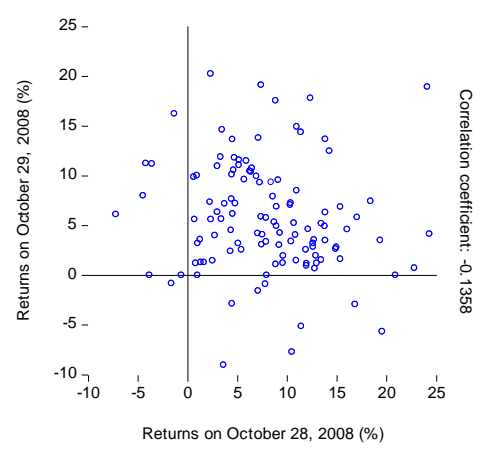

Panel F. October 31, 2008

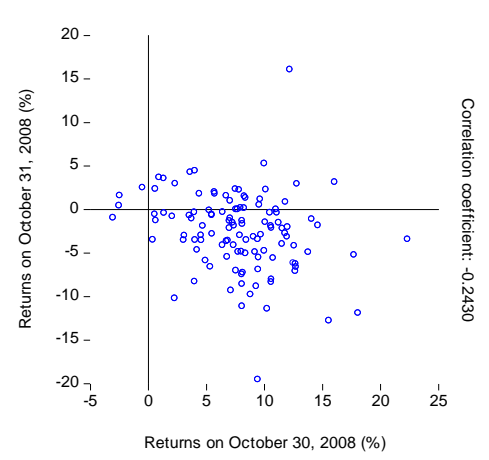

Panel H. November 7, 2008

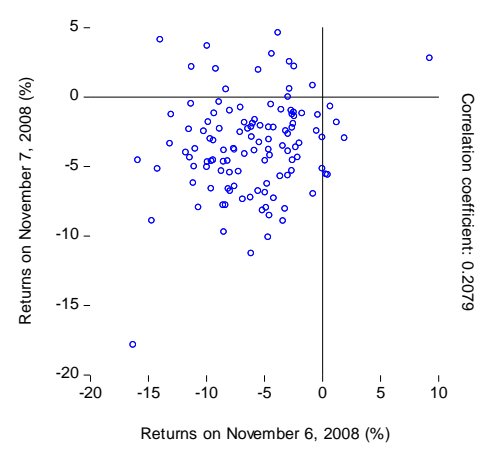

Panel J. November 20, 2008

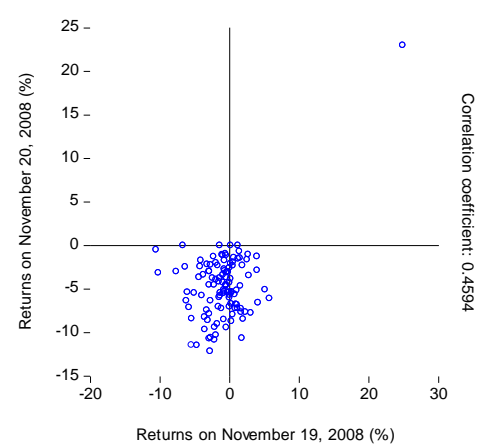


Panel K. November 21, 2008

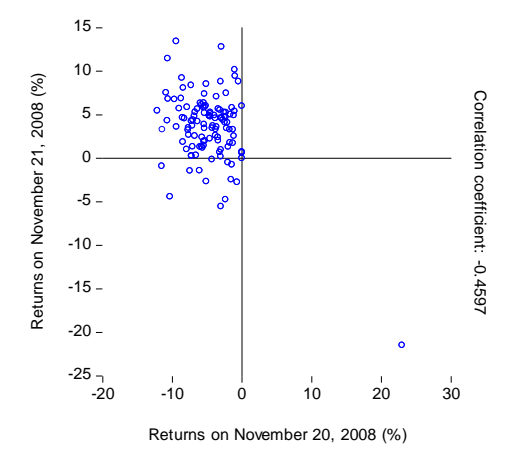

Figure 2. Japanese Electric Appliances Industry Returns of Two Successive Business Days

When Implied Volatility Exceeds 80.

\section{Conclusion}

This paper investigated whether weak form market efficient hypothesis holds in markets with deteriorated investor sentiment by focusing on the return dynamics of the Japanese electric appliances industry stocks. The empirical research demonstrated in this paper derived the following novel contributions.

1. First, this paper revealed that when investor sentiment is very stable in stock markets, two successive days' returns had no relation. Hence we understand that in markets with very stable sentiment, weak form market efficient hypothesis holds.

2. Second, we newly demonstrated that when investor sentiment is deteriorated, two successive days' returns presented statistically significant relations. Therefore, this evidence means that in markets with extremely declined investor sentiment, weak form market efficient hypothesis does not hold. This is the most important contribution in this paper.

As above, our novel findings documented in this paper will contribute to the body of academic researches of investments and asset-pricing fields in finance. We consider that future related studies using our findings and related data may be also valuable, and these researches are our future tasks.

\section{Acknowledgement}

The author acknowledges the generous financial assistance of the Japan Society for the Promotion of Science. In addition, the author thanks Nick Wade for his kindness to this paper. Further, the author thanks two anonymous referees for their kind and careful comments to this paper. Moreover, I greatly appreciate the repeated kind invitation of the Editors to write to this journal. 
Table 1. Regression results of the Japanese electric appliances industry returns of two successive business days when implied volatilities are extremely high or low

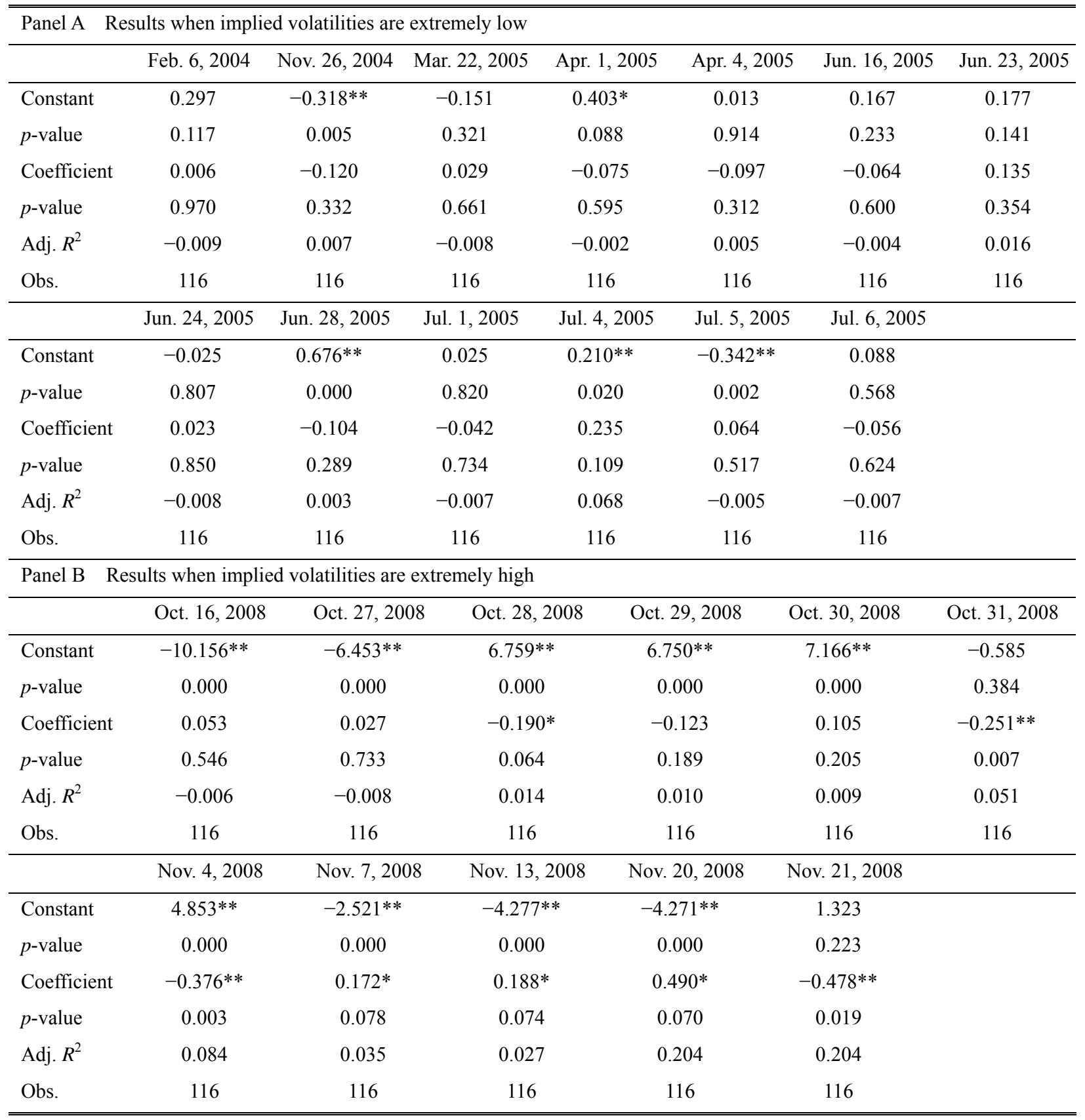

Notes: We use the return data of the Japanese electric appliances industry and implied volatilities derived from the Nikkei 225 options. Our full samples are 3,274 and the full daily sample period is from January 5, 1998 to April 28, 2011. We regard the markets when IV is less than 13.5 as stock markets with very stable sentiment. On the other hand, we regard the markets when IV exceeds 80.0 as stock markets with deteriorated sentiment. We perform the cross-sectional regressions for the days when market sentiment is stable (Panel A) and for the days when market sentiment is deteriorated (Panel B). In our regressions, dependent variables are the returns of the days when market sentiment is very stable or deteriorated, while explanatory variables are one day prior returns. Moreover, Adj. $R^{2}$ denotes the adjusted $R$-squared values and Obs. means the number of samples in our cross-sectional regressions. Further, we use the method of White (1980), thus $p$-values are robust to the heteroskedasticity of the error terms of regressions. ** denotes the statistical significance at the $5 \%$ level and $*$ denotes the statistical significance at the $10 \%$ level. 


\section{References}

Alimov, A., \& Mikkelson, W. Does favorable investor sentiment lead to costly decisions to go public? Journal of Corporate Finance, forthcoming. http://dx.doi.org/10.1016/j.jcorpfin.2012.02.004

Baker, M., \& Wurgler, J.A. (2006). Investor Sentiment and the Cross-Section of Stock $\begin{array}{llll}\text { Returns. Journal of } & \text { Finance, } & 61, & 1645-1680 .\end{array}$ http://dx.doi.org/10.1111/j.1540-6261.2006.00885.x

Baker, M., \& Wurgler, J.A. (2007). Investor Sentiment in the Stock Market. Journal of Economic Perspectives, 21, 129-151. http://dx.doi.org/10.1257/jep.21.2.129

Baker, M., Wurgler, J.A., \& Yuan, Y. Global, Local, and Contagious Investor Sentiment. Journal of Financial Economics, forthcoming. http://dx.doi.org/10.1016/j.jfineco.2011.11.002

Barberis, N., Shleifer, A., \& Vishny, R. (1998). A model of investor sentiment. Journal of Financial Economics, 49, 307-343. http://dx.doi.org/10.1016/S0304-405X(98)00027-0

Berger, D., \& Turtle, H.J. (2012). Cross-sectional performance and investor sentiment in a multiple risk factor model. Journal of Banking \& Finance, 36, 1107-1121. http://dx.doi.org/10.1016/j.jbankfin.2011.11.001

Brealey, R.A., Myers, S.C., \& Allen, F. (2008). Principles of Corporate Finance, Ninth Edition, The McGraw-Hill Companies, Inc., New York.

Daniel, K., Hirshleifer, D., \& Subrahmanyam, A. (1998). Investor Psychology and Security Market Under- and Overreactions. Journal of Finance, 53, 1839-1885. http://dx.doi.org/10.1111/0022-1082.00077

Fama, E.F. (1970). Efficient Capital Markets: A Review of Theory and Empirical Work, Journal of Finance, 25, 383-417. http://dx.doi.org/ 10.2307/2325486

Kurov, A. (2010). Investor sentiment and the stock market's reaction to monetary policy. Journal of Banking \& Finance, 34, 139-149. http://dx.doi.org/10.1016/j.jbankfin.2009.07. 010

Lee, C.M.C., Shleifer, A., \& Thaler, R.H. (1991). Investor Sentiment and the Closed-End Fund Puzzle. Journal of Finance, 46, 75-109.

Neal, R., \& Wheatley, S.M. (1998). Do Measures of Investor Sentiment Predict Returns? Journal of Financial and Quantitative Analysis, 33, 523-547. http://dx.doi.org/10.2307/2331130

Stambaugh, R.F., Yu, J., \& Yuan, Y. The short of it: Investor sentiment and anomalies. Journal of Financial Economics, forthcoming. http://dx.doi.org/10.1016/j.jfineco.2011.12.001

Tsuji, C. (2006). Does investors' sentiment predict stock price changes? With analyses of naive extrapolation and the salience hypothesis in Japan. Applied Financial Economics Letters, 2, 353-359. http://dx.doi.org/10.1080/17446540600690136

White, H. (1980). A Heteroskedasticity-Consistent Covariance Matrix Estimator and a Direct Test for Heteroskedasticity. Econometrica, 48, 817-838. 


\section{Copyright Disclaimer}

Copyright reserved by the author(s).

This article is an open-access article distributed under the terms and conditions of the Creative Commons Attribution license (http://creativecommons.org/licenses/by/3.0/). 